\title{
The Effect of Kayak Foot brace on Forward Stroke and Stability of Boat in the Kayak Sprinting
}

\author{
Chong-hoon Lee \\ Department of Sports Science, Seoul National University of Science \& Technology, \\ Seoul, Korea \\ leejh36@snut.ac.kr
}

\begin{abstract}
The aim of this study was to investigate the effect of kayak foot brace on forward stroke and boat's stability. Thirteen male elite kayak athletes participated in this study. They were divided two groups (Foot brace group; FB and no-brace group; NF). All Kayak athletes performed kayak sprinting on flat water condition. Stroke, duration time, knee joint ROM, trunk rotation ROM, and boat stability were measured and analyzed. The results showed that FB group's stroke duration time was significantly shorter than NF group's. Knee joint ROM, trunk rotation ROM were increased, and boat's roll angle ROM was decrease when using foot brace. The result can be utilized to design trunk ROM increasing training program.
\end{abstract}

Keywords: Kayak, Foot brace, Stroke, Joint ROM Kinematics, EMG

\section{Introduction}

In the Olympic kayak matches, one hundredth seconds can decide the color of the medals. The small winning margins are often related to equipment or technique. During kayak paddling, the force developed by the paddler is transferred to the kayak against a foot brace and seat. The foot brace and "swivel seat" that makes stroke easier are the most important part of the interior boat design. Kayak athletes generate propulsive force with forward strokes and the force should be effectively transferred through the foot brace in order to maximize outcome (Michael, J. S., Smith, R. \& Rooney, K. B., 2009).Previous studies focused on the relationship between foot brace and the rank of athletes in Olympic (Ackland et al., 2003; Alacid, Marfell-Jones, López-Miñarro, Martínez\&Muyor, 2011) and suggested that the foot brace is one of the key element for efficient kayaking. However, it is hard to find a study that investigated a specific technique needs for it. Investigating the role of foot brace could help improving kayaking performance and can be used for future design of the foot brace. The purpose of this study was to investigate the effect of kayak foot brace on forward stroke and boat's stability. Furthermore, the results could be used for development of the foot brace design.

\section{Method}

\subsection{Participants}

Thirteen male collegiate athletes were selected. They all had at least 4 years of kayaking experience. The participants were divided into two groups depending on usage of foot brace. Foot brace (FB) group had 8 participants and no foot brace (NB) group had 5 participants Table 1. 
Table 1. Subject Characteristics ( Mean \pm St.Dev. )

\begin{tabular}{cccc}
\hline Group & Subject & Height $(\mathrm{cm})$ & Body mass $(\mathrm{kg})$ \\
\hline \hline Foot Brace(FB) & $\mathrm{n}=8$ & $176.4 \pm 6.6$ & $74.1 \pm 7.1$ \\
No Foot Brace(NB) & $\mathrm{n}=5$ & $177.4 \pm 6.0$ & $74.1 \pm 7.1$ \\
\hline
\end{tabular}

\section{Experimental Setting and Equipment}

All participants performed kayak sprinting on flat water condition. An inflatable boat from Woosung I. B. co., was used ( $3.8 \mathrm{~m}$ x $0.7 \mathrm{~m}$, capacity: $193 \mathrm{~kg}$, weight: $12.5 \mathrm{~kg}$; Figure 1). A plastic paddle of $2.30 \mathrm{~m}$ length from the same company was used. Participants wore tight fitting clothes. Inertial measurement unit (IMU) sensor, developed by Korea Institute of Science and Technology (KIST) was used to capture the motions of foot brace group (FB). This IMU sensor was a combined sensor unit consisting of accelerometers (LIS3LV02DQ, SPI, 12bit), gyrosensor (L3G4200D, SPI, 16bit, 2000dps), and geomagnetic sensor (Figure 2). Gyrosensor produces angular velocity and rotational matrix of an object with respect to global reference frame. Accelerometers and geomagnetic sensors adjusts rotation matrix created by gyrosensor (Chun, Kang, Choi, Park, Lee \& Kim, 2013). In addition, motion capture of no brace group (NF) was performed by Myomotion ${ }^{\circledR}$ and MR3 ${ }^{\circledR}$ software (Noraxon, USA).

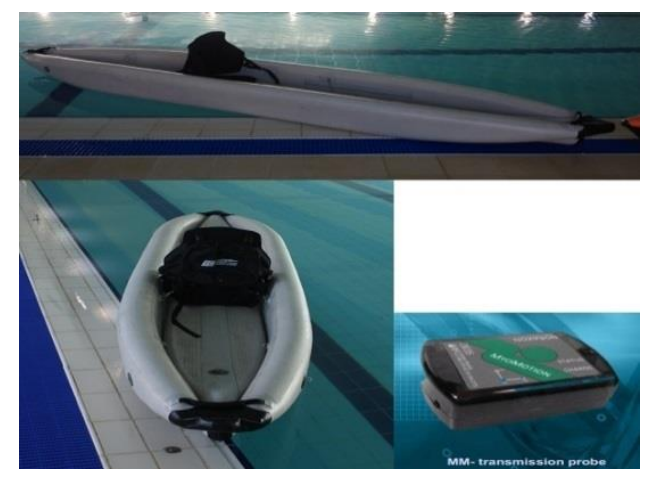

Figure 1. Portable(inflatable) Boat and NoraxonMyoMotionsensor

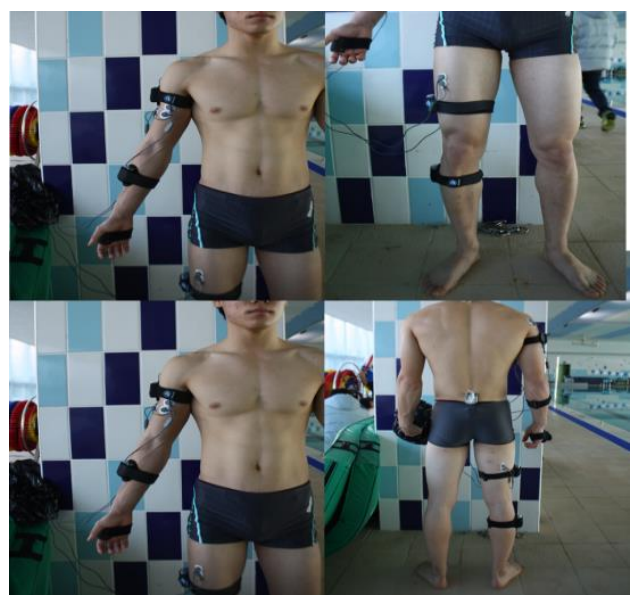

Figure 2. Attachment Placement of Gyro Sensor \& Electrode 


\subsection{Procedure}

All the participants were stretched and warmed up before testing. The sensors were placed on participants' trunk, thigh, and leg. They performed maximum effort forward strokes for 20 $\mathrm{m}$ at indoor swimming pool. Data were collected after initial $5 \mathrm{~m}$ phase. A 5 minute break was given between trials.

\subsection{Data Analysis}

Dependent variables were time duration of 1 stroke cycle, right knee angle ROM, trunk rotation angles, and ROM of rolling angle of boat Figure 3. SPSS version 20.0was used to perform independent t-test andalpha level was set at $<.05$.

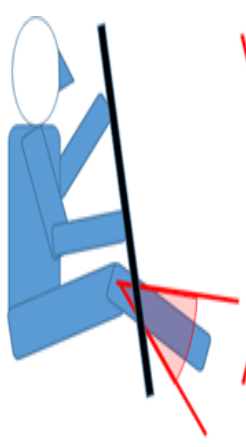

(A)

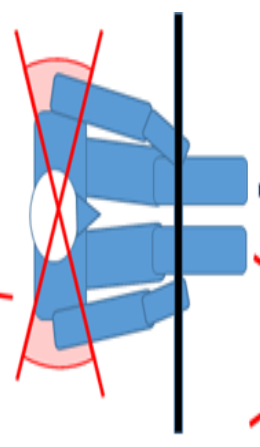

(B)

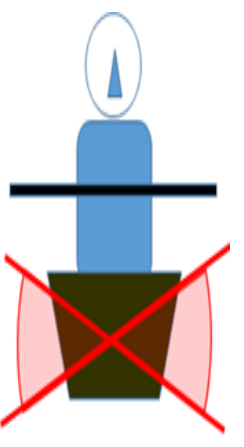

(C)

Figure 3. Definition of Experimental Variables (A) Range of Motion(RoM) of Knee Angle, (B) RoM of Trunk Angle in Transverse Plane, (C) RoM of Boat Rolling Angle

\section{Results}

\subsection{Stroke Performance (time duration of 1 cycle)}

Time duration of 1 stroke cycle was measured to examine the effect of foot brace on stroke performance <Table 2>와<Figure 4>. The foot brace group demonstrated significantly shorter time duration of 1 cycle $(\mathrm{p}=.0001)$.

Table 2. Forward Stroke Performance Time Duration of 1 Cycle Forward Stroke

Foot Brace(FB) No Foot Brace(NB) P value

\begin{tabular}{|c|c|c|c|}
\hline \multirow{2}{*}{$\begin{array}{l}\text { Time duration of } \\
1 \text { cycle[sec] }\end{array}$} & 1.06 & $1.43^{*}$ & \multirow{2}{*}{.0001} \\
\hline & $(0.096)$ & $(0.16)$ & \\
\hline
\end{tabular}




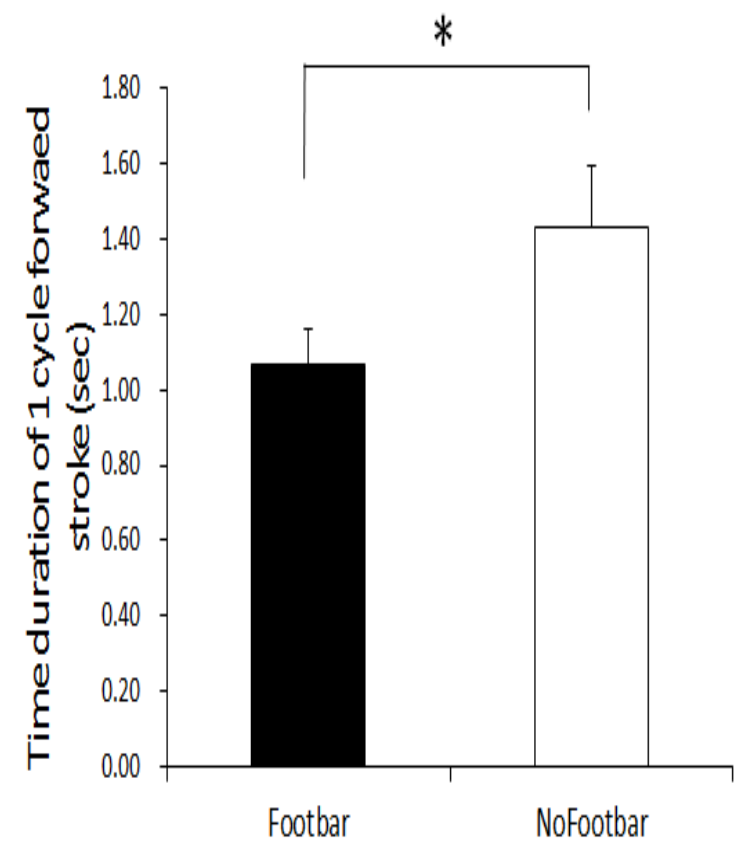

Figure 4. Time Duration of 1 Cycle Forward Stroke

\subsection{Kinematics and Boat Stability During Forward Stroke}

Knee joint ROM angle (Right side) indicates amount of lower body movement during stroke and trunk movement was examined with trunk rotation angles in transverse plane Table 3, Figure 5. ROM of rolling angle which represents the angle of boat moving in lateral direction measures stability of kayak boat. The knee joint angles, trunk rotation angles, and boat ROM of rolling angles significantly decreased with FB condition $(\mathrm{p}=.039, \mathrm{p}=.004$, and $\mathrm{p}=.001$, respectively).

Table 3. Joint Angle, RoM and Rolling Angle (mean \pm SD)

\begin{tabular}{llll}
\hline & Foot Brace(FB) & No Foot Brace(NB) & P value \\
\hline \hline $\begin{array}{l}\text { Joint Range of Motion [deg] } \\
\text { Right Knee Joint angle }\end{array}$ & $14.32 \pm 4.37$ & $35.06 \pm 27.94$ & .039 \\
$\begin{array}{l}\text { Trunk rotation in transverse } \\
\text { plane }\end{array}$ & $19.56 \pm 7.95$ & $34.21 \pm 7.45$ & .004 \\
$\begin{array}{l}\text { Stability of Kayak Boat } \\
\text { ROM of Rolling angle [deg] }\end{array}$ & $11.54 \pm 4.63$ & $2.90 \pm 1.75$ & .001 \\
\hline
\end{tabular}



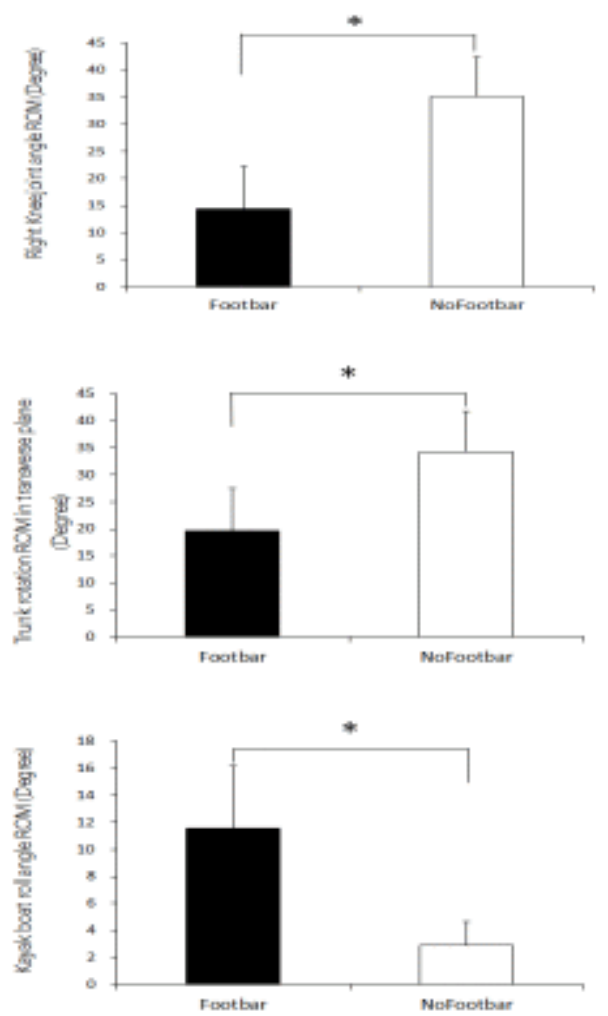

\section{Figure 5. Joint angle, RoM and Rolling Angle (mean \pm SD)}

\section{Discussion and Conclusion}

This study investigated the effect of kayak foot brace on forward stroke mechanism and boat's stability. Shortened time duration of 1 stroke cycle with FB condition indicates that the foot brace increases frequency and speed of stroke. The results suggest that the foot brace helped transferring power against extending knees and increasing stroke speed.

The boat ROM of rolling angles was smaller in NF condition. Athletes push off opposite foot during forward stroke. However, in the absence of foot brace, less power and lateral movement were created. This information can be utilized by athletes. If one could develop a method to control the lateral stability with the foot brace, it would help increasing speed of boat with less resistance.

The trunk rotation in NB condition resulted in increased trunk rotation. Considering the argument by Michael et al., (2009) that trunk rotation is one of the essential movements for forward stroke, training without foot brace can be utilized to enhance trunk rotation of athletes. Using trunk rotation rather than shoulder extension can allow athletes to use bigger muscles to obtain propulsive force.

Considering that minimizing drag resistance with greater stability needs to be obtained as well as maximizing propulsive force to achieve best performance (Kendal \& Sanders, 1992), the result of this study can be used for development of foot brace and training for kayak athletes. 


\section{Acknowledgements}

This study was supported by the Research Program funded by the Seoul National University of Science and Technology (2014 - 0853).

\section{References}

[1] T. R. Ackland, K. B. Ong, D. A. Kerr and B. Ridge, "Morphological characteristics of Olympic sprint canoe and kayak paddlers", Journal of Science and Medicine in Sport, vol. 6, no. 3, (2003), pp. 285-294.

[2] F. Alacid, M. Marfell-Jones, P. López-Miñarro, I. Martínez and J. Muyor, "Morphological characteristics of young elite paddlers", Journal of Human Kinetics, vol. 27, no. 1, (2011),pp. 95-110.

[3] J. Banks, A. B. Phillips, S. R. Turnock, D. A Hudson and D. J. Taunton, "Kayak blade-hull interactions: A body force approach for self-propelled simulations", Proceedings of the Institution of Mechanical Engineers, Part P:", Journal of Sports Engineering and Technology, (2014).

[4] M. Begon, F. Colloud and P. Sardain,"Lower limb contribution in kayak performance: modelling, simulation and analysis", Multibody System Dynamics, vol. 23, no. 4, (2010), p. 38400.

[5] S. Kendal and R. Sanders,"The technique of elite flatwater kayak paddlers using the wing paddle", International Journal of Sport Biomechanics, vol. 8, (1992), pp. 233-250.

[6] J. H. Lee, J. J. Ryu and K. J. Nam, “An Analysis of the Kayak Stroke According to Skill Level”, Journal of the korean society of sports science, vol. 21, no. 4, (2012), pp. 1389-1401.

[7] J. S. Michael, R. Smith and K. B. Rooney, "Determinants of kayak paddling performance", Sports Biomechanics, vol. 8, no. 2, (2009), pp. 167-179.

[8] Olympic.org. (2013).Olympic.org's Canoe/Kayak sprint equipment and history. Retrieved January 30, 2013, from http://www.olympic.org/canoe-kayak-sprint-equipment-and-history?tab= History.

[9] K. B. Ong, T. R. Ackland, P. A. Hume, B. Ridge, E. Broad and D. A. Kerr, "Equipment set- up among Olympic sprint and slalom Kayak paddlers", Sports Biomechanics, vol. 4, no. 1, (2005), pp. 47-58.

[10] K. B. Ong, B. Elliott, T. R. Ackland and A. Lyttle, "Performance tolerance and boat set- up in elite sprint Kayaking”, Sports Biomechanics, vol. 5, no. 1, (2006), pp. 77-94.

[11] S. Plagenhoef, "Biomechanical analysis of Olympic flatwater kayaking and canoeing", Research quarterly, vol. 50, no. 3, (1979), pp. 443.

[12] B. R. Ridge, E. Broad, D. A. Kerr and T. R. Ackland, "Morphological characteristics of Olympic slalom canoe and kayak paddlers", European Journal of Sport Science, vol. 7, no. 2, (2007), pp. 107-113.

\section{Author}

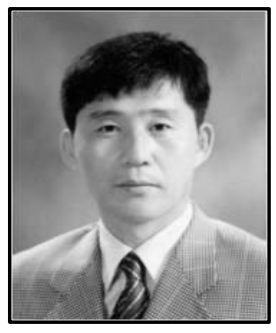

Chong-Hoon Lee

Dept. of Sports Science

Seoul National University of Sciences \& Technology

138 Gongreung-gil, Gongreung2-dong 172, 139-743 Korea

Email: leejh36@snut.ac.kr 